\title{
An Investigation of the Palma Ratio for Turkey Both on National and Regional Level
}

Emine TAHSIN (https://orcid.org/0000-0003-0349-2381), Department of Economics, İstanbul University, Turkey; e-mail: tahsin@istanbul.edu.tr

\section{Türkiye İçin Palma Oranının Ulusal ve Bölgesel Düzeyde Analizi}

\begin{abstract}
This paper aims to focus on concentration of income inequality in case of Turkey, based on the Palma ratio that is calculated as the ratio of the share of the top 10 percent income to the bottom 40 percent income. In this regard for the post-2001 period, the income shares of the deciles in Turkey both on national and regional (NUTS-1) level would be analyzed. It would be predicted that, this would provide more specific evidences about the dimensions of the hidden inequality. Within this context based on the descriptive statistics and income inequality decomposition analysis, robustness of the Palma ratio would be evaluated. While overlapping trend between the Palma ratio and the Gini coefficient is found to be significant both on national and regional level, the top 10 percent income group represents the most distinctive feature in determining concentration of income inequality between and within the regions of Turkey.
\end{abstract}

Keywords

Income Inequality Metrics, The Palma Ratio, Regional Income Distribution in case of Turkey, Income Inequality Decomposition.

JEL Classification Codes : $\quad$ E25, O1, O5, R1.

\section{$\ddot{\mathbf{O z}}$}

Bu çalışma, en üstteki yüzde 10'luk gelir diliminin en alttaki yüzde 40'lık gelir dilimine oranı olarak hesaplanan Palma oranını temel alarak Türkiye'de gelir eşitsizliği yoğunlaşmasına odaklanmayı amaçlamaktadır. Bu kapsamda, 2001 sonrası dönem için gerek ulusal gerekse bölgesel (NUTS-1) düzeyde ondalık gelir dilimlerine ilişkin veriler temel alınacaktır. Bundan yola çıkarak gelir eşitsizliğinin esas olarak nerede gizlendiği hakkında daha belirgin sonuçlara ulaşılacağ öngörülmektedir. Çalışmada, betimleyici istatistikler ve gelir eşitsizliği ayrıştırma yöntemi ile ulaşılan bulgulara dayanarak, Palma oranının temelleri sınanmaktadır. Bulgular sonucunda gerek ulusal gerekse bölgesel düzeyde Palma oranı ile Gini katsayısı arasındaki değişim eğiliminin belirgin bir şekilde örtüştügü görülürken, en üstteki yüzde 10'luk gelir grubunun payının, bölgelerarası ve bölge içindeki eşitsizlikleri belirleyen en temel gelir grubu olma özelliğine sahip olduğu ortaya çıkmaktadır.

Anahtar Sözcükler $\quad$ : Gelir Eşitsizliği Ölçütleri, Palma Oranı, Türkiye'de Bölgesel Gelir Dağılımı, Gelir Dağılımı Ayrıştırması. 


\section{Introduction}

This paper is concerned with one of the income inequality metrics that is called the Palma ratio, based on Turkey's both national and regional level data for the period of 20022017 and 2006 -2017 respectively. Based on Gabriel Palma's empirical observation (2006, 2011, 2013, 2014a, 2014b, 2016), the Palma ratio is calculated as the ratio of the income share of the top 10\% (Decile 10, as the richest) compared to that of the bottom $40 \%$ (total, Decile 1-Decile 4, as the poorest) ${ }^{1}$. Hence main features of the Palma ratio suggest that the difference in the income distribution of different countries is largely the result of changes in the top and bottom 'tails' of the distribution as there tends to be relative stability in the share of income that goes to the 'middle' groups (total, Decile 5-Decile 9) (Cobham \& Sumner, $2015)^{2}$.

Regarding complementary function of different inequality metrics that provide a general framework (UNDESA, 2015), this paper would not suggest that the Palma ratio is the best inequality metrics. Definitely the concept of inequality is itself a proposition that involves differentiating it from a certain level of equality (Şenesen, 1998: 245). Thus the choice of income inequality metrics requires understanding the strengths and weaknesses of each metric that is preferred over others and even the criterion used for comparison includes normative preferences as well (Atkinson, 2003; Cowell, 2000).

In this case the choice of analyzing inter-decile income changes with respect to the Palma ratio is mostly concerned with the academic interest that recognize the idea of generating alternative metrics matters for better understanding of income inequality concentration. As it should be underlined that the use of different income inequality metrics instead of the Gini coefficient, that is most traditionally and commonly used, undoubtedly is not a new phenomenon. This paper's motivation of analyzing inter-deciles income figures is founded upon the two main facts.

Primarily while the Gini coefficient reduces the whole distribution to a simple number only ${ }^{3}$ (Atkinson, 2003: 23) at the same time it is defined as a metric that is more sensitive to changes in the middle groups ${ }^{4}$. Secondly developments in the collection of more homogenous household income and consumption data covering more countries has increased the quality of the inequality measurement that also simultaneously contributes to

1 Each income decile has 10 per cent of the population. Income deciles is ranked from the lowest income tenth (D1) to highest income tenth (D10-top 10) as D1, D2, D3, D4, D5, D6, D7, D8, D9, D10.

2 Since then, the Palma ratio is also used in OECD's income distribution database (Cingano, 2014; OECD, 2014), in the UNDP Human Development Report (2015, since 2015), in the World Bank Global Monitoring report (2015) and in some national statistics (e.g. the UK, ONS, 2015), as an indicator of development goals and income inequality metrics (Cobham \& Sumner, 2015: 1).

3 While Sen, Atkinson and Theil indexes constitute the most basic example of this, comparing income deciles as a criterion of concentration of income inequality has been commonly accepted.

4 Empirical evidence on this topic is out of the scope of this paper. For recent debates see (Gastwith, 2017). 
the empirical investigation of inequality. Briefly empirical evidences on global scale indicates that gains and losses for each income group (either quintiles or deciles) differs and as a consequence of these; the necessity of focusing inter-groups income change rather than Gini coefficient has been more significant (Deininger \& Squire, 1996; Bourgingon \& Morrison, 2002; Stucfille, 2003; Milanovic, 2005; Milanovic, 2016). Furthermore, based on the World Top Income Project and the works of Atkinson, Piketty and Saez (2011), the income-wealth relation and inequalities among income deciles have been accepted to be more decisive in defining inequalities. As it is figured out since 1980 the share of the top $1 \%$ has reached twice as high as the income of the lowest 50\% (WIR, 2018: 9) and such outcome also indicate that comparative analysis of income deciles for analyzing the concentration of income inequality could be a precondition. As a consequence of the mentioned preliminary studies these evidences have also triggered the question of how the bottom and top deciles benefit from the gains in economic growth. As Voitchovsky $(2005,2009)$ had shown out that Gini coefficient would not be enough to set up the link between income inequality and economic growth, while different income groups such as the bottom and top deciles have been affected differently.

Summing up, within the framework of the paper, the Palma ratio is examined as an income inequality metric that covers changes in income deciles at opposite "tails" that is commonly suggested to be more critical for a deeper analysis of income inequality concentration.

For the case of Turkey, the main contribution of this paper is an investigation of income deciles regarding the main features of the Palma ratio, as an alternative inequality metrics. As Tahsin (2013) has already investigated the Palma ratio for the period between 2002-2013, first of all this paper covers a longer period of time for the analysis and furthermore includes regional, NUTS-15, level to the analysis. In doing so, this paper primarily reveals the robustness of the Palma ratio in respect to the Gini coefficient. In addition, it contributes to the sub- regional decomposition of inequalities based on the features of the Palma ratio by using the Mahalanobis distance, $R_{B}$ (Between group inequality) and $\mathrm{G}_{\mathrm{within}}$ (within group inequality) calculations.

In the following sections, primarily empirical evidence and debates on the Palma ratio will be summarized. In the latter sections of the paper; studies on income distribution in Turkey would be outlined and information on the selected data and methodology of the paper would be given. As a further step by using descriptive statistics, the Mahalanobis distance calculations and sub-regional decomposition analysis, main features of the Palma ratio and income inequality concentration in Turkey would be estimated. section. 


\section{Empirical Evidence on the Palma Ratio}

Primarily, the Palma ratio (2006) examines global inequality in a cross-sectional country analysis framework and argues that the Gini coefficient is insufficient in explaining the dynamics of income inequality under $21^{\text {st }}$ century conditions and that new criteria should be developed instead.

In the first study that Gabriel Palma outlined "the Palma ratio", he suggested (2006) that data sets with a 20 percent (quintiles) share of income do not have satisfactory results for income inequality; he uses income deciles data in order to compare dynamics of income inequality at global, regional and national level. Palma (2013), for the first time, uses the WDI (World Development Indicators) data of 2012, from 131 countries as a starting point for the "Palma ratio" ranking. According to this, the Palma ratio, with the lowest value, is found to be 0.8 in Sweden and it is calculated as 8.5 in South Africa which is the highest value.

In the analysis conducted using WDI data (2004), the Gini coefficient ranking of 109 countries, the regional median value of the Gini coefficient, D10 and D9 rankings are compared. While the Gini coefficient values reveal regional income inequality differences, high values of range and standard deviation for D10 is found to be striking. On the other hand, the gap between D9 and D10 also shows the size of the difference between the two income groups, while D10 has a range value that is six times greater than D9's range value. Another important finding is that the D9 median values for countries are similar, while the D10 median values are quite different (Palma, 2006: 3-4). Additionally, D10/D1 range values apparently receive greater values differently from the other metrics (D9/D2, Q4/Q2 and Q3/Q2) (Palma, 2006).

An analysis of the descriptive statistics for income decile groups of the countries in the WDI data set, indicate heterogeneity in the share of D1-D4 and D10, and homogeneity in the share of middle deciles which is defined as a striking contrast (Palma, 2006: 9). The coefficient of variation of D10 to D1-D4 is approximately 4 times larger than the coefficient of the variation of D5-D9 which introduces the differences among income deciles groups more concretely.

According to these results, Palma emphasizes the necessity of looking "into the Gini" as well as the Kuznets inverse U hypothesis by also examining and using the decile income groups instead of the Gini coefficient. Accordingly, the similarity of the relationship between the Gini coefficient and the per capita income (ln GDPpc 1997, 1995 US dollar) and between the per capita income and the D10 per capita income is observed, while the relationship between D1-D4 and per capita income is found to be a mirror image of the relationship between D10 and per capita income (Palma, 2006: 9; 2011: 11, 15). Furthermore, the relationship between D5-D9 and per capita income indicates more homogenous trends for the regions. This similarity is also observed for the upper middle income (D7-D9) and is considered to be a surprising result (Palma, 2006: 19; 2011). 
On the basis of these results, Palma argues that while income inequality varies among countries, in the population of the countries that are composed of 4 layered segments; half of the population represents D10 and D1-D4 and the other half represents homogeneity in income distribution (D5-D9, D7-D9). Palma (2006: 12) puts forward a thesis of homogeneity of middle-income deciles in the neoliberal era, and in countries with high inequality, he suggests that D10 is subsidized by income share of D1-D4 even though it is observed that D10 also determines the share of the middle deciles (Palma, 2018: 7, 13).

Palma explains the dynamics of income inequality by pointing out the existence of two opposing forces that is "centrifugal" D10, D1-D4 and "centripetal" (D5-D9) forces. While "centrifugal" forces cause divergence in the share of D10 and D1-D4, "centripetal" forces represent convergence in income. Palma (2013), stylizes the fact that the most important phenomenon is related to the share of the rich and furthermore he underlines that the income distribution is determined by the struggle in the tails. On the basis of this proposal, he supports that the main policies determining the share of tails would be efficient to eliminate inequalities.

Following Palma's studies, Cobham and Sumner (2013a, 2013b, 2015) empirically investigated the propositions of the Palma ratio. Based on PovcalNet data (1990, 2010, 2012) Cobham and Sumner point out the strong correlation between the ratio of the Palma ratio and the Gini coefficient even though it is revealed that the Gini coefficient is over sensitive to the Palma ratio (2013b: 143).

When the relationship between the initial values of Gini coefficient and Palma ratio; and the absolute proportional change of both coefficients between 1990-2010 is empirically tested for 76 countries, stickiness of inequality has been confirmed, and that the initial level of Palma has had a strong impact on the absolute and proportional change level, despite the 20-year period (Cobham \& Sumner, 2013: 9). Additionally, when the question of to what extent components of the Palma ratio explain the change in the Gini coefficient is examined, it is extrapolated that the change in the Gini coefficient explains the Palma ratio components by 98 percent. (Cobham \& Sumner, 2013a, 2013b).

In the light of the empirical results, the Gini coefficient is found to be over sensitive to the Palma ratio even when the Palma ratio is found to be more sensitive to the changes in income deciles. From this point of view, it is predicted that the Palma proposition provides sufficient evidence to overcome the bias of the Gini coefficient, (Cobham \& Sumner, 2013b: 143).

However, it is emphasized that the Palma ratio should be seen as a group inequality analysis. It is stated that the Palma ratio does not have decomposition features and does not permit change within the groups (Cobham \& Sumner, 2015: 9), and might not explain what is happening to middle income deciles. With regards to this, Hazledine (2014) questions the rigidity of the middle-income deciles. The given answer to this critic, Palma (2014) underlines that he refers to the relative stability of middle deciles compared to other income deciles. Milanovic (2015) points out that the measurement of inequalities in this ratio may 
be problematic for later periods, and states that time is needed to get excited about the Palma ratio. In his criticism of the Palma ratio, he underlines the fact that this ratio is based on an axiom which is insensitive to transfers between the income groups and neglect sub-grouping divisions.

Other main critical points of the Palma ratio are about the limited potential of showing progress among the bottom $5 \%, 10 \%$, and $20 \%$ while it is more sensitive to changes in D10 (Lenhard \& Shepard, 2016). As Ravallion argues (2015, cited by Murawski, 2016) the Palma ratio will continue to increase if an increase in the bottom share and an even greater increase at the top would raise the index rating, even though the recovery in share of the poor's income may not be noticed. Cobham and Sumner respond to this approach and point out that except Burundi there is no other country that fits this sampling (2013c).

Furthermore, the Palma ratio has triggered a question of measurement of inequality metrics as a political tool in order to decrease inequality. Krozer (2015) raises an additional ratio based on the findings of the Palma ratio, suggesting that this may be complementary to the Palma ratio. Accordingly, when the ratio of the first 5\% to bottom 40\% (Palma V.2) and the ratio of the first $1 \%$ to bottom $40 \%$ (Palma V.1) is calculated, the dimensions of the divergence within the first 10\% become apparent. Lars-Enberg Pedesen (2016) is of the opinion that the Palma ratio can be functional in determining the content of development policies, especially taxation, social services and so on. In the World Bank's shared Prosperity study (2016: 53), the Palma premium (p) is defined as the difference between the growth in the mean of the bottom $40 \%$ and the growth in the mean of the D10 ( $\mathrm{p} \equiv \mathrm{g} 40$ g10). Hereby, a positive Palma premium suggests that a given country has experienced narrowing income inequality. Doyle and Stiglitz (2016) suggested a 1\% Palma ratio by the year 2030; that would mean that the data can be used in poverty reduction strategies as part of the post-2015 development goals. Based on this proposition, Palma (2018) took anchor in countries with a ratio of 1 to 1 and calculates how much countries should have a share of D10 for the Palma 1 target, while part of the D10, above the Palma 1 target, receives data (D10+) as the degree of concentration of inequality.

Summing up the logic of the Palma ratio is defined as emphasizing the importance of "tails" in accounting for the diversity of income inequality in the world and is expressed as a result of the need to draw attention to the artificial foundations of inequality. Thus, this metric suggested that we focus on the dynamics that determine asymmetries in income distribution dynamics.

\section{Income Distribution Studies in Turkey}

The post-2001 period of the Turkish economy refers to higher GDP growth rates that comprise of theoretical and institutional policy shifts, both in distribution and redistribution policies, that would not be discussed in detail within the framework of the paper. This period is also accompanied by regularly announce of individual- household income data; Household Budget Survey (HBS), Income and Living Conditions Survey (SILC) by TurkStat that also contribute research on income distribution in Turkey. For the post-2001 
period, factor income distribution, wage earnings inequality, wealth accumulation, effects of redistribution policies on income distribution, dynamic decomposition of household level data, income mobility, socioeconomic level of differences determining income inequality, consumption and income inequality, regional disparities could be classified among the main titles covered by income distribution studies.

Considering the income inequality data based on the Gini coefficient, it can be seen that the trend of inequality decreased considerably in the period 2002-2007 (Selim \& Günçavdı \& Bayar, 2014), but this trend reverted again after the 2008-2009 crisis and it has increased in the period after 2014 (see also figure 1).

However, it must be known that the main findings of the income distribution studies covering the post-2001 period reveal the necessity of considering the economic growth tendency within sub-periods as subordinated to interest, exchange rate and inflation policies. Considering the GDP growth rate figures of Turkey, a significant increase (average 8.1\%) was realized between 2002 and 2007. As a result, during that period, GDP per capita had doubled. In the aftermath of this period, the world economic crisis in 2008 affected growth rates negatively. For the period between 2002-2012, the average growth rate is calculated as $5.1 \%$, although, after 2014, more moderate growth rates have been achieved (2014-2017 average $3.9 \%$ ) (TurkStat, 2018).

Apparently, increasing rates in GDP per capita rates were observed during this period, meanwhile, on regional (NUTS-1) and province level, it is possible to suggest that a stable convergence had been realized (Oz, 2017; Karaca, 2018). Besides, studies focusing on regional inequalities underline that the main source of income inequality in Turkey is not because of regional income differences, but within regional inequalities (Bayar, 2016; Filiztekin, 2015; Selim et al., 2014; Filiztekin \& Celik, 2010; Yıldırım \& Öcal, 2006; Gezici \& Hewings, 2004; Doğruel \& Doğruel, 2003). When it is focused on regional income dynamics, roots of disparities could be explained depending on economy policies, migration, labor market conditions, earning inequality and other factors related to income generation (Sefil-Tansever \& Kent, 2018; UNDP, 2016; Bayar, 2016; Selim, et al., 2014).

Prominent factor incomes are found to be one of the main determinants of income inequality for both national and regional levels (BSB, 2015; Selim et al., 2014). Especially property rents, interest incomes and entrepreneur shares have been identified as the main factors that have more contribution to inequality both on a national and regional level (Selim, et al., 2014; Dayioglu \& Başlevent, 2005, 2006). Earning differences also, has been examined on regional level; position in occupation together with the education, economic sector and gender has been analyzed in order to figure out total earnings inequality between and within NUTS-1 level regions of Turkey (Sefil-Tansever \& Kent, 2018).

In general, studies that focus on functional income distribution points out that profits have been more critical in the determination of inequality, whereas labor earnings has 
increased during 2003-2006 period. Eksi and Kırdar (2015), Bakış and Polat $(2015)^{6}$ focus on labor earnings and wage-inequality for a period of 2002-2011 and 2002-2010 period respectively. These studies analyze the wage-labor earnings inequality compared with different level of percentiles of income, age and education. The main findings of these studies also indicate that wage-labor inequality has decreased due to increase in minimum wage during 2003-2006 although this trend has altered during the 2007-2011 period, figuring that this trend has affected upper tail (either the ratio of percentile 90 to percentile 50 or percentile 90) and lower tail (either the ratio of percentile 50 to percentile 10 or percentile 10) wage levels differently depending on age and education as well. Additionally, Tamkoç and Torul (2018) has investigated the wage, consumption and income inequality trend for the period of 2002-2016 and aim to define the determinants of wage inequality on the basis of residual component of wage, gender and experience premiums. For this period, it is concluded that gender and experience premiums, as well as the residual component of wage decreases over time and income and consumption inequalities exhibit the similar timetrends.

Furthermore, Tansel et al. (2014), has set up the link between wage inequality and wage mobility for the period of 2005-2011 and it is specified that although there is increase in real wage, this increase has limited effect on wage mobility to reduce wage inequality. Especially it is underlined that lower wage group did not benefit from the wage increase and among higher educated households, women and older households wage inequality are found to be higher. Additionally, the question of whether income mobility has contributed to income equality has been investigated in Turkey for the period of 2005-2010 (Güven et al., 2016). Based on gender, age, education and income quintile groups, main evidences of this study also point out that mobility varies at the tails of the distribution.

Besides dynamic decomposition of household income data has been investigated by Filiztekin (2015). Filiztekin (2015) decomposes household income data over age, gender, education, occupation, household type, regional disparities, and income structure for the period of 1994-2011. One of the evidences of this study that is related to this paper's title is about the pattern of the 90th-to-median ratio that is very similar to the Gini coefficient implying that changes in equality, mostly due to convergence or divergence in the upper half of the distribution (Filiztekin, 2015: 67). On the other hand, it is revealed that the differences between rural and urban household are important and regional policies in the last decade is suggested to be effective to reduce inequality between regions. Although Filiztekin (2015: 88) also underlines that after 2007 rapid increase in within regional inequality questions the success of these policies.

The accumulation of wealth (BSB, 2015; WIR, 2018; Başlevent, 2018; Torul \& Öztunal1, 2018) has also increased during post- 2001 period, which has triggered the 
question of dimensions of inequality among income groups, especially focusing incomewealth relations. On international level Turkey's income-wealth inequality is found to be high (Torul \& Öztunal1, 2018) and household level household assets show the highest contribution to individual inequality (Başlevent, 2018).

Moreover, it is seen that institutional changes in redistribution policies differentiate the dynamics of income distribution, but the level of recovery in income inequality is still questionable. It is possible to mention that the new social assistance regime that accompanies the growth regime of Turkey has consequences in favor of the poor (Başlevent, 2014; Tekguç, 2018), but at limited levels both on a national and NUTS-1 level. Bahçe and Köse (2017) also underlines that higher proportions of transfer income goes to upper income level of households compared to lower income of households. In addition to these studies, based on the general dynamic model, Yakut and Voyvoda (2017) have demonstrated that increasing budget allocations to unilateral social transfer programs has no significant effect on the size distribution of income and has adverse effects on the labor market decisions of relatively poor laborers.

As TurkStat already conducts the income quintile share ratio of S80 to S20 (top income quintile share to the bottom quintile) as a case of inter-quintile comparison, investigation of income distribution dynamics based on different percentiles ${ }^{7}$ have been also on the agenda of the various studies (etc. Bakış \& Polat, 2015; Güven et al., 2014; Tansel et al., 2014; Selim et al., 2014; Filiztekin, 2015; Eksi \& Kırdar, 2015; UNDP, 2016; Tamkoç $\&$ Torul, 2018). It could be noted that both on national and regional level Atkinson and Theil indexes have been additionally used as alternative metrics to the Gini coefficient. Moreover, at regional level, the decomposition of household data to outline between and within regional inequalities have been decisive. Within this context, different income inequality metrics such as Atkinson index (Dayioglu \& Başlevent, 2006) for analyzing the role of the imputed rents; sub-population decomposition based on Jenkins (1995) methodology considering household characteristics such as gender and education (Bayar, 2016); and Theil index for decomposing earnings inequality (Sefil-Tansever \& Kent, 2018) have been utilized.

Summing up, based on mentioned studies, it could be suggested that two opposite tendencies on the basis of income inequality concentration have been mostly challenged. The main findings of these previous studies lead us to investigate opposite tendencies (such as the ratio of the top income deciles against to bottom income deciles) in income distribution dynamics, hence it is thought that income deciles and the Palma ratio would be valuable to focus on.

7 Such as the ratio of upper percentile to bottom percentiles; percentile 90 to percentile 10 , percentile 90 to percentile 50, percentile 50 to percentile to percentile 10 and ratio of S80/S20. 


\section{Data and Methodology}

Related to the data relevant to the Gini coefficients, there are some specific facts that should be underlined for Turkey's case. The Gini coefficient data is derived from TurkStat, which has announced figures "regularly" only since 2002, and the absence of regular data prior to 2002 means that a comparison for a longer time period is not possible. Given the methodological problems of household income data sets ${ }^{8}$ in this paper, continuity, homogeneity and universal acceptance of data sets will be taken into consideration. For this purpose, the PovcalNet data set for the period 2002-2016 will be included in the analysis and mainly the equivalized household data of the Income and Living conditions survey (SILC) conducted by TurkStat since 2006 will be used both for the national and regional (NUTS-1) level.

Apart from the WDI, PovcalNet is classified among the main data sets that comprise most widely used comparable harmonized household data at an international level (Smeeding \& Latner, 2015). The database maintained by the PovcalNet team in the World Bank's Development Research Group mainly focuses on poverty estimations for 164 economies. Differently from the WDI, PovcalNet also comprise of micro household data at income decile level at the national level. The distributional data used here are drawn from nationally representative household surveys which are conducted by national statistical offices or by private agencies and obtained from government statistical offices and World Bank Group operational departments. Briefly, the PovcalNet data re-estimates national household survey data according to their own methodology. Due to this, in tracing out the entire distribution PovcalNet also warns about the estimation of the income deciles (PovcalNet, 2018).

Considering the regional level data of Turkey, NUTS-1 level, that comprise of 12 sub-regions (units), would be used based on the principles of continuity of the data. It should be noted that in Turkey for the purpose of harmonization of the statistical sytem of the European Union (EU), three stage regional system planning of Eurostat has been implemented since 2002. The Eurostat NUTS system is defined as a geographical nomenclature subdividing the economic territory into regions. Three different levels; NUTS 1,2 and 3 respectively, moving from larger to smaller territorial units according to the sizes of population by considering economic, social, cultural, geographical and other factors has been classified (Eurostat, 2018). Based on this, Turkey (TR) has 81 provinces in NUTS-3 units, 26 sub-regions in NUTS-2 units and 12 sub-regions in NUTS-1 units. Twelve subregions in NUTS-2 level is classified as; İstanbul region (TR1),West Marmara region (TR2), Aegean region (TR3), East Marmara region (TR4), West Anatolia region (TR5), Mediterranean region (TR6), Central Anatolia region (TR7), West Black Sea region (TR8), 
East Black Sea region (TR9), Northeast Anatolia region (TRA), Central East Anatolia region (TRB), Southeast Anatolia region (TRC) (TurkStat, 2018).

In this paper for both data sets, apart from using officially announced Gini coefficient data, the income share of the deciles for the estimation of the Palma ratio would be utilized. Based on these, first of all, to analyze changes in inter-income deciles, descriptive and explanatory statistics will be utilised for percentage shares, the Gini coefficient and the Palma ratio. Additionally, the mean values of the relevant deciles (total mean income and mean income of D10, D1-D4, D5-D9) ${ }^{9}$ will also be included in the analysis. In this context, rather than analyzing absolute improvement, proportional change in mean values of income deciles, with respect to total mean income and GDP per capita income (TurkStat, 20062017) will be examined both on a national and NUTS-1 level. In this retrospect, the Palma premium (p) will be taken into consideration.

In doing so, the robustness of the Palma ratio with reference to the Gini coefficient will be investigated. While analysing descriptive statistics for both income deciles and mean income data, the existence of "outliers" will be examined. For this purpose, in order to examine regional disparities on the basis of income deciles, the Mahalanobis distance calculation will be estimated for the percentage share values of the deciles. Given that the Mahalanobis distance allows computing ${ }^{10}$ the distance between two points (here the distance between TR and other given NUTS-1 level region) in a p-dimensional space, while considering the covariance structure across the p dimensions (XTLAS, 2014). Briefly, the Mahalanobis distance is calculated for a two-dimensional vector with no covariance.

The square of the Mahalanobis distance $\left(\mathrm{dM}^{2}\right)$ is written as;

$$
\mathrm{dM}^{2}=(\mathrm{x} 1-\mathrm{x} 2) \sum-1(\mathrm{x} 1-\mathrm{x} 2)
$$

(Equation 1)

Here the first part of the equation 1 is the vector xi and in the second part $\sum$ is the covariance matrix. In doing so, $\mathrm{x} 1$ would be equal to TR values and $\mathrm{x} 2$ would be equal to relevant NUTS-1 level values. So that proximity of regions to TR that is to say to what extent regions either diverge or converge to TR's level would be evaluated. As a further step, a regions' contribution to total inequality would be investigated in order to give answers on dimensions of income inequality concentration, based on income deciles. In this case, subpopulation decomposition for 'between inequality' $\left(\mathrm{R}_{\mathrm{B}}\right)$ (Bhattacharya \& Mahalanobis, 1967 cited by Giorgi, 2011: 10-11) and 'within inequality' $\left(\mathrm{G}_{\text {within }}\right)$ would be utilised (Bellu $\&$ Liberati, 2006). While $\left(\mathrm{R}_{\mathrm{B}}\right)$ captures the inequality due to the variability of income across

9 Reel mean values adjusted according to 2003 Consumer Price Index of Turkey.

10 XTLAS (2014) has been used for this analysis and rejected Ho hypothesis; "the means vectors of the 13 classes are equal", for all samples. 
different groups, the $\left(\mathrm{G}_{\text {within }}\right)$ element would explore the inequality due to the variability of income within each group (Bellu \& Liberati, 2006).

For the $\mathrm{R}_{\mathrm{B}}$ analysis; the total mean of income recipients in income class (i) within group (j) (i.e income deciles within NUTS-1 level) would be compared according to the mean income of recipients in TR. Both for $R_{B}$ and $G_{\text {within }}$ estimations, mean values of relevant income deciles would be weighted according to their population share ${ }^{11}$.

In this case, in order to examine the overall trend, mean values of $R_{B}$ and $G_{w i t h i n}$ calculations would be considered for the period 2006-2017. Hence, classification of income deciles on the basis of contribution to income inequality would be outlined.

The formula for the $\mathrm{R}_{\mathrm{B}}$ analysis is written as;

$$
\begin{aligned}
& \mathrm{R}_{\mathrm{B}}=\sum_{i=1}^{k} \sum_{\mathrm{j} \neq \mathrm{i}} p i q j \frac{|\mu i-\mu j|}{\mu i+\mu j} \\
& j=\text { group } \mathrm{j} \text { with and } j=1,2, \ldots, k ; \\
& i=\text { income class with } i \text { in group } j=1,2, \ldots, h ; \\
& \mathrm{n}=\text { Population size of } \mathrm{TR} ;
\end{aligned}
$$

nj: Population share of group j(NUTS-1 level);

$p i=\mathrm{nj} / \mathrm{n}$ share of recipients in group $j$;

$\mu j=$ mean income of group $j ;$

$\mu i=$ mean income of income class $i$ in group $j$;

$\mathrm{qj}=\mathrm{pj}(\mu j / \mu)$, total income share of group $j$;

The formula for $\mathrm{G}_{\text {within }}$ analysis is written as;

$\mathrm{G}_{\mathrm{within}}=\left(\frac{n i}{n} \frac{y i}{y}\right)$ GininUTS-1

Given that;

11 Given that number of households for Income and Living Conditions surveys is weighted according to population share of regions' for percentage share of income deciles(Eq.1) weighting according to population is omitted although for (Equation,2) and (Equation, 3) samples are weighted according to population share. For weighting mean income values, population share of NUTS-1 level regions address-based population registration system data has been used (TurkStat, 2018). 
GininUTS-1 $_{\text {Gini value for NUTS-1 region; }}$
$\frac{n i}{n}=$ population share of each income class in group $j$.
$\frac{y i}{y}=$ the income share of each income class in group $j$.

Summing up, investigation of the data sets comprises of three main features, which are interpretations of descriptive statistics, whilst considering proportional change in income deciles, defining outliers by means of the Mahalanobis distance and $R_{B}$ and $G_{\text {within }}$ analysis for mapping regional disparities that is suggested to contribute towards income inequality concentration both on a national and regional level in Turkey.

\section{Comparison of the Gini Coefficient and the Palma Ratio for Turkey}

Taking into account both data sets (PovcalNet data, TurkStat) for Turkey, it is seen that the Palma ratio ranges from 2.17 to 1.68 in the period from 2002 to 2017 . According to the 2016 figures of the PovcalNet data, the Palma ratio for Turkey is 1.91, that is, the second highest value (after Chile) among OECD members, on a global scale, based on figures of the Palma ratio (Palma, 2018), Turkey could be classified among the "medium-level inequality" group.

For the 2002-2016 period (PovcalNet data) only the Palma ratio is found to be left (negative) skewed and for the years between 2006-2017 (TurkStat data) both metrics are positively skewed with negligible outliers ${ }^{12}$.

Based on the TurkStat and PovcalNet data set, a comparison of the Gini coefficient and the Palma ratio for Turkey is shown (see figure 1.1, 1.2). As seen from figure 1.1, both metrics have a tendency to decrease after the 2003 period especially in the period 20032006. In the Aftermath of 2013, a tendency to increase has been observed. Briefly, it is possible to classify different tendencies in inequalities depending on sub-period of economic growth tendencies of the Turkish economy. More importantly, it is striking that this trend of the Palma ratio is overlapping with changes in the Gini coefficient ${ }^{13}$.

As it is shown from figure 1.1 and 1.2, changing trends both in the Palma ratio and Gini coefficient are completely the same. Both the Gini coefficient and Palma ratio receive the maximum and the minimum values, in the same years. Moreover, the correlation among two variables is found to be very strong (as it is seen in figure 2.1 and 2.2). For the PovcalNet

12 Regarding the sample size graph box analysis has been considered but not included.

13 As mentioned in the data and methodology section, PovcalNet re-estimates the national household data sets. Also note that TurkStat has gone some methodological change in the collection of the household data after 2005. Briefly PovcalNet data follows the same trend but with different values compared to TurkStat data. 
data set, this correlation is calculated as (0.9887) and the TurkStat data set as (0.9984) at a $95 \%$ confidence level.

Figure: 1.1

Palma Ratio and Gini Coefficient

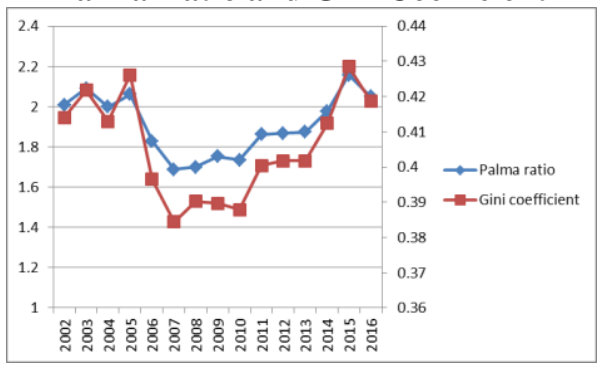

(PovcalNet, 2002-2016)

Figure: 2.1

Correlation of Gini Coefficient and Palma Ratio

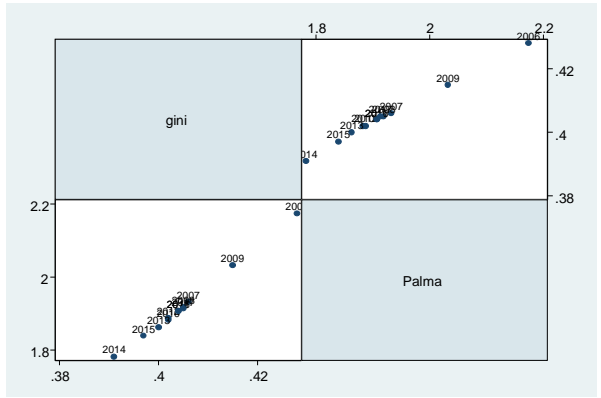

(TurkStat, 2006-2017)
Figure: 1.2

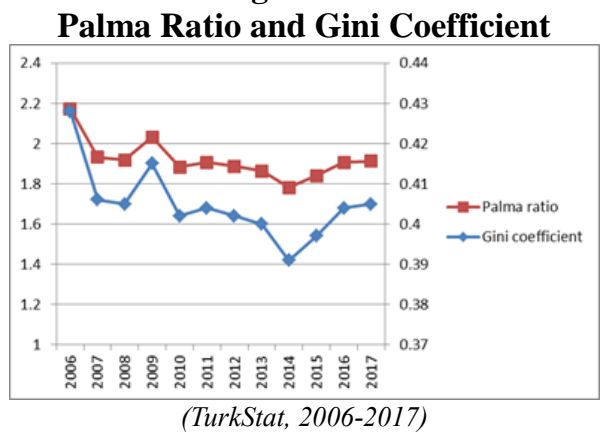

Figure: 2.2

Correlation of Gini Coefficient and Palma Ratio

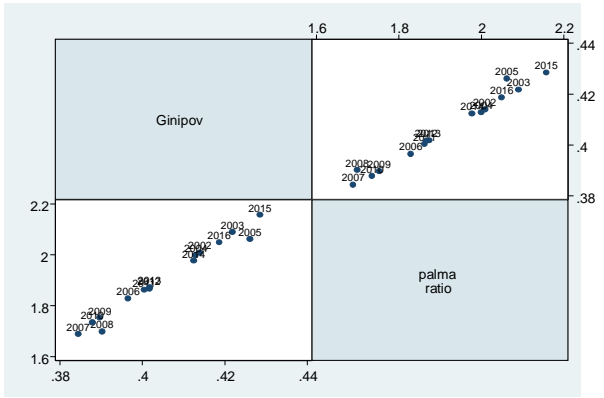

(PovcalNet, 2002-2016)

In addition to these, the rate of change (either increase or decrease for different periods) is more stationary for the Gini coefficient rather than the Palma ratio ${ }^{14}$. When proportional change for both the Palma ratio and the Gini coefficient with respect to the total mean income and GDP per capita were examined between the 2006-2017 period; the Palma ratio is found to be more sensitive to changes (negative values for both metrics has been calculated $)^{15}$. Nevertheless, the period covered by the PovcalNet data proportional change

14 Rate of change for Gini coefficient is only (0.02) and for Palma ratio is (0.14) for Povcal data set period. For period 2006-2017 rate of change for Gini coefficient is calculated as (-0.057) and for Palma ratio it is (-0.06).

15 Change in Palma ratio with respect to mean income is (-0.027) and GDP per capita income is (-0.02). Change in Gini coefficient with respect to mean income is (-0.022) and GDP per capita income is (-0.027). Once more, correlation with proportional change with Palma and Gini coefficient is found to be strong. 
with respect to mean income is found to be positive ${ }^{16}$, indicating temporary recovery in inequalities for a longer time period. As an overall result it could be suggested that after the post 2001 period in spite of increase in total mean and GDP per capita, recovery in inequality has been stationary. Moreover, when proportional change is examined annually, both metrics have negative and positive values for the same period and during the crises period of 2008-2009, sensitivity to changes in GDP per capita income is found to be higher for both coefficients ${ }^{17}$.

An evaluation of descriptive statistics also reveals that the Palma ratio has got 2 times higher standard deviation and coefficient of variation values than the Gini coefficient that lead us to explore relevant income deciles (see appendix). Hence, in the light of descriptive statistics and strong correlations between two variables, the explanatory power of the Palma ratio, with respect to changes in income deciles, will be investigated in the following sections.

\section{Comparasion of Centripetal and Centrifugal Deciles of Turkey}

In this section, given the basic features and propositions of the Palma ratio, questions of whether the income inequality is concentrated in "tails" and on the other hand, the proposition of the relative stability of the D5-D9 income deciles, will be examined for the TR level.

For the periods covered by TurkStat and the PovcalNet data set, the results are consistent with the proposition of the Palma ratio, that is; half of the income is shared by middle deciles and the other half of the income is shared among the tails. For both data sets, it is seen that D5-D9 shares do not fall below 50 percent. Moreover, this tendency indicates that the share of middle deciles is the reverse mirror image of the tails (see Figure 3.1 and 3.2). When the sum of the tails (D1-D4 and D10) has the lower ratio, the middle deciles take higher ratios, hence, it could be suggested that the tails and the middle deciles are substitutes of each other. For the period covered by PovcalNet data, it is seen that D5-D9 deciles share increased between 2005 and 2008 (maximum value in 2008) and later on this trend had been reversed. In the period covered by TurkStat data, the share of D5-D9 deciles have the highest ratio in 2007, although this ratio has decreased in the following periods.

Focusing on tails for both of the data sets' periods, it is seen that the lowest D10 share also means the highest D1-D4 share. When D10 has maximum value $(2002,2006)$, both D1D4 and D5-D9 has a reverse trend. In the period when D10 reaches the maximum level, the Palma rate is also the maximum.

16 For Palma ratio (0.02) and Gini coefficient (0.01).

17 For 2002-2016 period relation between GDP per capita and Gini coeffiecient and Palma ratio is expected to have - $U$-relationship. 
Figure: 3.1

\section{Centripetal and Centrifugal Deciles of} Turkey

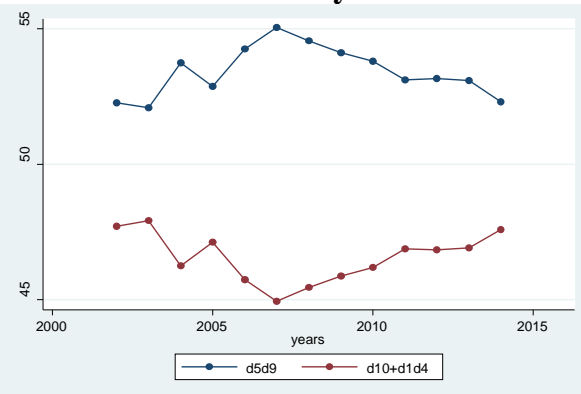

(PovcalNet, 2000-2016)
Figure: 3.2

\section{Centripetal and Centrifugal Deciles of} Turkey

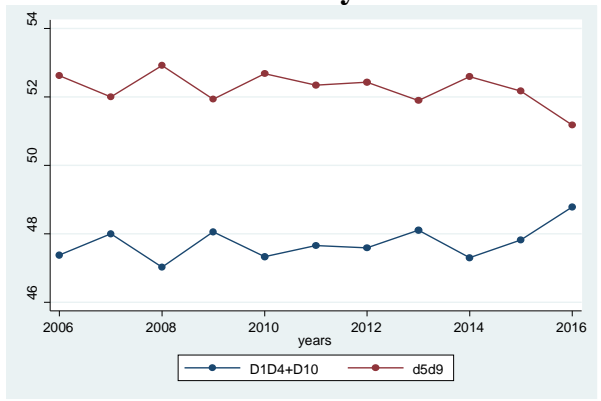

(TurkStat, 2006-2017)

For the Palma ratio covered by the TurkStat data period, the correlation between D1 D4 is found to be stronger (-0.95) than the correlation with D10 income deciles (0.85). On the other hand, the PovcalNet data set correlation between the Palma ratio and D1-D4 is (0.9492) and the correlation with the Palma ratio and D10 is stronger (0.9766).

However, one differing result for both data sets is with regards to the correlation between D5-D9 and D1-D4. Relatively, a lower correlation for D5-D9 and D1-D4 income deciles is noteworthy and the correlation between D5-D9 and D10 is found to be stronger and negative. Moreover, components of the Palma ratio have a stronger tendency to change against the Gini coefficient compared to middle income deciles and the correlation between the middle deciles and the Gini coefficient is found to be weaker. Including the fact that the D10 income decile has a negative and high correlation value with middle deciles.

According to the descriptive statistics, when the standard deviation and coefficient of variation values are taken into consideration, one of the specific features that stands out (for both data sets) is the higher standard deviation and range values for the D10 decile compared to the others. According to the PovcalNet data descriptive statistics, values for D10 are approximately 2 times higher than the period covered by the TurkStat data set. It is observed that D10 showed more variation in the period between 2002-2016.

As one of components of "tails", D1-D4 income deciles trend of change differs according to the covered period in both data sets whereas D5-D9 income deciles have relative stability. The standard deviations of both income groups are closer to each other between the years 2006 and 2017 (TurkStat data period). When the PovcalNet data set period is considered, the standard deviation for middle deciles is found to be higher than the bottom deciles. However, the coefficient of variation has the lowest values for D5-D9 in both data sets.

According to the data sets, after the aftermath of the 2008 crisis period, it is observed that the share of D10 has increased its share compared to the others. Furthermore, for the 
last years covered by data sets, the trend to increase in D10's share has been observed. Moreover, when we look at the ventile income groups (income groups ranking according to 5\% shares) for the period 2006-2017 (TurkStat, 2018), the differentiation "within the D10 income group" is notable. Consequently, V20 (first 5\% income share) values are double those of V19 $\left(19^{\text {th }}\right.$ ventile, second 5\% income share) values. Furthermore, this figure has a 3 times higher standard deviation than V19, that leads us to recall the importance of the Palma ratio V.2 to analyze the degree of concentration of the inequalities as mentioned in Krozer's (2015).

Clearly, the different trend of income deciles could be interrupted with answers given to the question of who has benefited from the increase in GDP per capita and the total mean income. In this case, due to the period covered by the data sets, the results indicate that two different trends could be extrapolated (as mentioned in the previous section). Given that the PovcalNet data set covers the post-2001 period of Turkey, between the years 2002 and 2016 the proportional change in the share of D1-D4 is found to be negative which is an opposite trend when compared to other income groups and even for middle deciles this change is found to be the highest. Although for the period between 2006-2017 the Palma premium indicates a different trend in income deciles ${ }^{18}$. Even proportional change in the D1-D4 total mean with respect to the total mean income is found to be higher than the others. Meanwhile, the proportional change in the middle deciles with respect to the total mean income and GDP per capita, income is found to be weaker compared to the others. Clearly, it could be suggested that considering the sub-periods of GDP growth, the middle deciles share increased in the previous years but in the aftermath, this has decreased whereas the share of D10 has increased continuously and the recovery in the bottom deciles has been temporary.

As a result, the centrifugal forces have been more volatile and relative stagnation of the centripetal forces has been justified. On the other hand, among centrifugal forces, it could be suggested that evidently D10 income group has the potential of squeezing other deciles. While focusing on the Palma ratio components and relevant income groups, these facts could become more pronounced.

\section{Regional Level Comparison of the Palma Ratio and the Gini Coefficient}

For the post-2001 period, acceleration of the rate of GDP per capita has also led to a limited level of convergence among regions. For the period 2006-2017, regions real GDP per capita has increased to above $2 \%$. Even proportional change in GDP per capita income has been above Turkey's average for regions (TRC), (TRB), (TR4) and (TR1) (that is above 3 percent) compared to other regions and a lower increase has been realized for (TR9). (TR1) apparently has the highest GDP per capita (approximately one third of TR's GDP per capita) income, whereas regions above the intra-regional mean of GDP per capita income are (TR2), 
(TR3), (TR4), (TR5), (TR6) and the others are below the intra-regional mean of GDP per capita income; (TRA) with lowest GDP per capita mean ${ }^{19}$.

Figure: 4.1

Real Total Mean Income (NUTS-1)

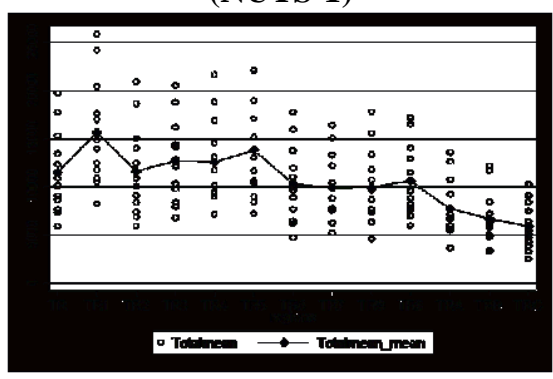

(TurkStat, 2006-2017)
Figure: 4.2

\section{Overall Mean of $\mathbf{R}_{\mathrm{B}}$ Analysis for Total Mean}

Income (NUTS-1)

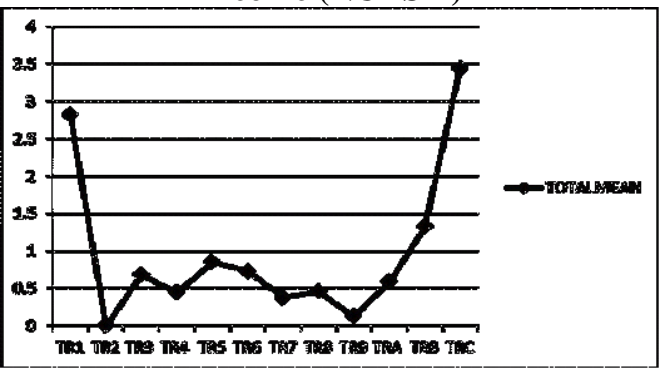

(TurkStat, 2006-2017)

Within this context, regions could be classified according to total mean values that are either above or below TR's mean income level (see fig.4). When the average of the mean income levels is taken into account, it is found that, (TR1) (highest mean income) and (TRC) (lowest mean income) regions indicate two opposite trends. (TR5), (TR3), (TR2) and (TR4) regions own higher average mean income levels than the intra-regional average. Besides, proximity of the average mean income level among (TRA), (TRB) and (TRC) regions is clearer, having said that these regions own the lowest average mean income levels compared to others.

Given that, according to 'between' group analysis for total mean income, ranking in descending order, (TRC), (TR1), (TRB), (TR5), (TR6), (TR3) and (TRA) regions are found to have a higher contribution (above 0.5 ) to total mean income inequality in Turkey ${ }^{20}$ (Equation 2, Fig. 4.2).

Given these facts, considering intra-regional distribution for the Gini coefficient and the Palma ratio, no outlier figure has been detected. In addition to this, the skewness test for both metrics indicates normal distribution. However, while inter-regional figures have been examined, varieties in skewness have been observed.

As can be seen from figure 5 and figure 6 , the mean and range values taken by the Palma ratio over time reveal the existence of intra-regional heterogeneity. For the period of 2006-2017, Turkey's mean of the Palma ratio is calculated as (1.92), while the intra-regional

19 Due to limited space GDP per capita table has not been included.

20 For (TR1) (2.82), TR(0.001), (TR3) (0.68), (TR4) (0.44), (TR5) (0.85), (TR6) (0.733), (TR7) (0.37), (TR8) (0.45), $\operatorname{TRA}(0.58)$, (TRB) (1.32), (TRC) (3.43). 
mean of the Palma ratio is (1.61). For the Gini coefficient, whilst the mean of Turkey is (0.40), the intra-regional mean for the Gini coefficient has a lower value (0.37). While (TR6) region has the highest mean value (1.84) of the Palma ratio, (TR2) region has the lowest mean value (1.42). This tendency is observed to be similar with mean values of the Gini coefficient. As seen in figure 6, for both the Palma ratio and the Gini coefficient, the regions that are above and below the intra-regional mean value are completely overlapping, indicating the same trend relevantly for both ratios.

\section{Figure: 5}

\section{Palma Ratio and Palma Mean of Turkey and Regions}

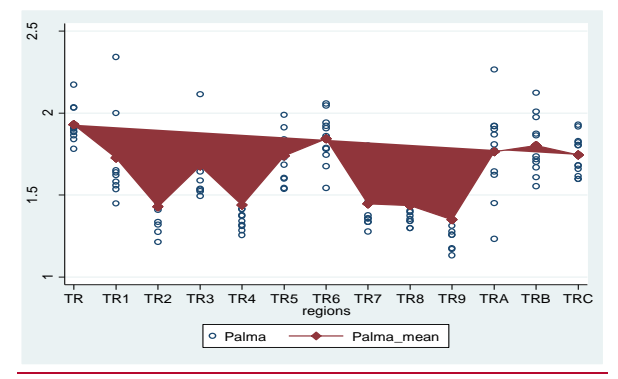

(TurkStat, 2006-2017)

Accordingly, when the Palma ratio's mean values are taken into consideration, it is possible to mention three main trends on NUTS-1 regional level (see fig 6.1 and 6.2). Regions could be divided into sub-groups (almost the same for the Gini coefficient's mean value); a) regions relatively close to the TR mean and above the intra-regional mean value (1.61), (TR6) (1.84), (TRB) (1.80), (TRA) (1.76), b) regions above and proportionally closer to the intra-regional mean, (TRC) (1.73), (TR5) (1.73), (TR1)(1.72), (TR3) (1.67) c) regions below the intra-regional mean value, (TR9) (1.35), (TR2) (1.41), (TR4) (1.43) (TR8) (1.43) (TR7) $(1.44)^{21}$.

As a result of chart outlying mean values (fig. 6) and Mahalanobis distance calculation (Eq.1, fig. 7), overlapping trends between the Palma ratio and the Gini coefficient is clearly observed. Beyond that, the regions away from TR are found to be the regions where the Palma ratio is lower, while the regions close to TR are found to be the regions where this ratio is higher. Furthermore, as seen in figure 7, regions that are closer to TR's values also contribute more to the total mean income inequality (see figure 5) and their Palma ratio mean is found to be above the intra-regional mean.

21 For this case I prefer to include TR values as well to make a comparison, when TR values is omitted ranking of NUTS-1 regions do not change. Just red lines (intra-regional mean) level changes. 
Figure: 6.1

Means of Palma Ratio and Gini

Coefficient

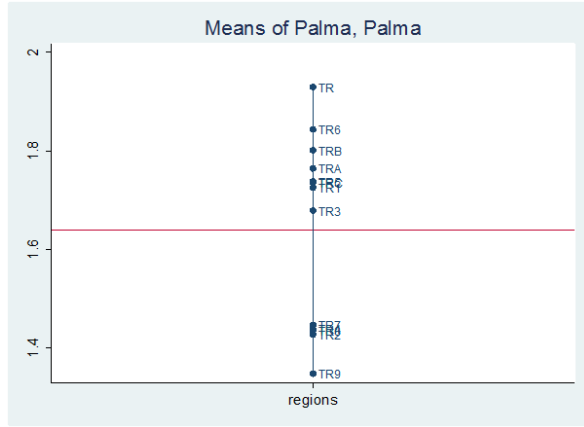

(TurkStat, 2006-2017)
Figure: 6.2

Means of Palma Ratio and Gini Coefficient

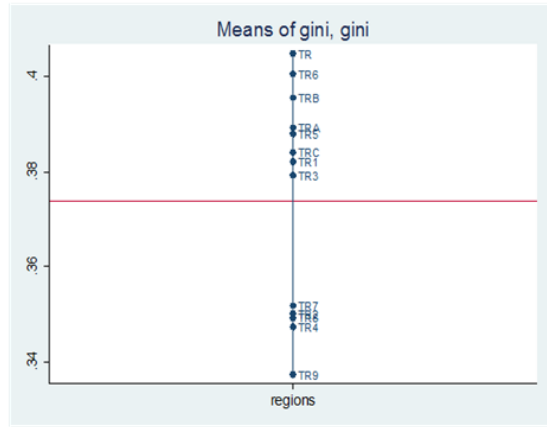

(TurkStat, 2006-2017)

Figure: 7

Mahalanobis Distance for Palma Ratio and Gini Coefficient (NUTS-1)

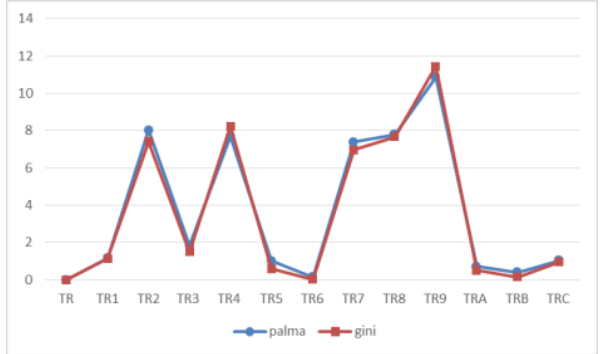

(TurkStat, 2006-2017)

Figure: 8

Correlation of Gini Coefficient and Palma Ratio (NUTS- 1)

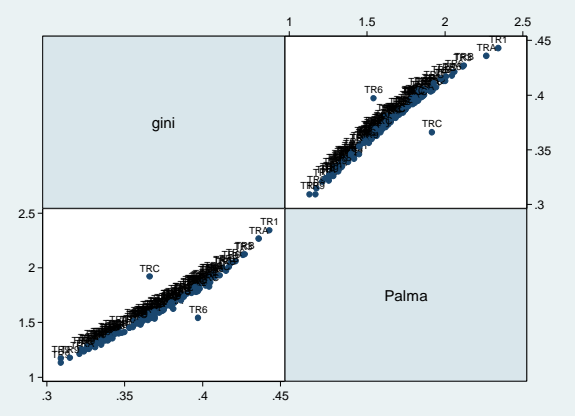

(TurkStat, 2006-2017)

Furthermore, as seen from figure 8, the intra-regional correlation between the Gini coefficient and the Palma ratio is found to be strong (0.98) at $95 \%$ confidence interval, whereas the inter-regional correlation except the (TRC) (0.6920) and (TR6) (0.8224) regions 
indicates a strong correlation similar to intra-regional correlation figures. As a consequence of the given results, the question of why a different trend has occurred in the (TRC) and (TR6) regions will be discussed in the following section.

While considering inter-regional ${ }^{22}$ and intra-regional range values for both metrics once more, the heterogeneous structure of income inequality is clarified. The inter-regional difference between maximum and minimum range values for the Gini coefficient is (2) times higher, while this figure is (2.5) times higher for the Palma ratio. Regions having the highest (TRA), (TR1) and the lowest range (TRC) values for both metrics are overlapping.

On the other hand, the standard deviation and coefficient of variation values for the Palma ratio are found to be higher than the Gini coefficient. One of the most prominent features of the descriptive statistics is about the coefficient of variation of the Palma ratio that indicates a higher rate compared with other income groups.

Given the mean, range, standard deviation and coefficient of variance values for the Palma ratio, changes in (TRC) and (TR2) region is found to be more stationary while (TRA) and (TR1) regions indicate a higher level of volatility compared with other regions. Arranging the mean of standard deviation of regions also indicates an overlapping tendency with the Palma ratio and the Gini coefficient, whereas (TRA) and (TR1) are the regions with the highest standard deviation for both metrics, and regions with the lowest standard deviation (TRC), (TR2) for the Palma ratio also have a lower standard deviation.

When proportional change with respect to mean income and GDP per capita income is considered, the Palma ratio is found to be more sensitive compared to the Gini coefficient for NUTS-1 level as well. For the (TR1) and (TR2) regions, proportional change for both metrics is found to be positive, which is different from other regions and TR. Additionally, sensitivity to changes in the Palma ratio, with respect to total mean income, reaches its highest value in (TR1) and (TR2). The negative trend with highest sensitivity compared to other regions is relevant for (TR3). As a result, it could be suggested that the increasing trend in GDP per capita and total mean income became a determinant in (TR1) and (TR2) regions and the opposite for (TR3). This could be interpreted as amendatory. Hence, the Palma premium for (TR1) and (TR2) is found to be negative ${ }^{23}$ (different from other regions) and the highest Palma premium ratio belongs to (TR3) region ${ }^{24}$.

Briefly, the overlapping trend of the Palma ratio with respect to the Gini coefficient is found to be strong, meanwhile, regions with a higher Palma ratio are found to contribute to total inequality more. Regarding the evaluation of both of the metric's estimations, 
outliers could be interrupted; so, for a deeper analysis of income inequality, concentration, centripetal and centrifugal forces will be investigated.

\section{Centripetal and Centrifugal Deciles on Regional Level}

For the period 2006-2017, dispersion of the Palma ratio components and the middle -income deciles reveal a more complex picture in terms of inter and intra -regional income inequality. Regarding this complex picture this section aims to clarify the basic facts with regards to the trend of dispersion in income groups and aims to set up linkages with trends of change in the Palma ratio and the Gini coefficient. Primarily, for all three income groups, on an intra-regional level, the existence of outlier figures is insignificant. Although on an inter-regional level, outliers for all income groups exist but only a few, so descriptive statistics would be utilized.

As seen in figure 10 (see appendix), the mean values for the centrifugal forces vary differently from TR's mean values. Although the mean values for the centripetal forces indicate a more homogenous income distribution. Remarkably, due to the distribution of the centrifugal and centripetal forces "two separate segments" exist. The Mahalanobis distance calculations for income groups' percentage shares also confirm this suggestion (see fig. 9, Eq.1). The proximity and homogeneity of the regions on the basis of D5-D9 share of TR's is evident, although the values for the centrifugal deciles indicate a more diversified structure. Even for the bottom deciles, dispersion seems to be more diversified according to TR's.

Figure: 9

\section{Mahalanobis Distance for Income Deciles (NUTS-1) (\%) (2006-2017)}

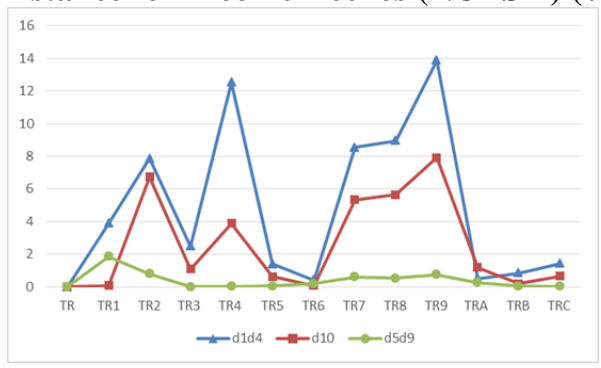

When the intra-regional mean values of the D1-D4 and the D10 income deciles are taken into consideration, it is seen that the regions below the intra-regional mean and the regions remaining above are displaced, but there is no one-to-one overlap. The intra-regional mean value for D10 is calculated to be below TR's mean, while D1-D4 regional mean value is found to be above TR's mean.

For D10, (TR6, (31.34)) has the closest mean to TR, while the lowest mean value belongs to (TR9, (26.79)). The (TR9) region with the lowest Palma ratio also has the lowest mean value for D10 and the highest mean value for D1-D4 (17.10). The regions with the 
lowest D10 mean are found to be the regions with the lowest Palma ratio and Gini coefficient mean. Adding that region (TR6), with the highest mean values of D10 has also the highest mean value for the Palma ratio.

Figure: 10

\section{Centripetal Deciles on NUTS-1}
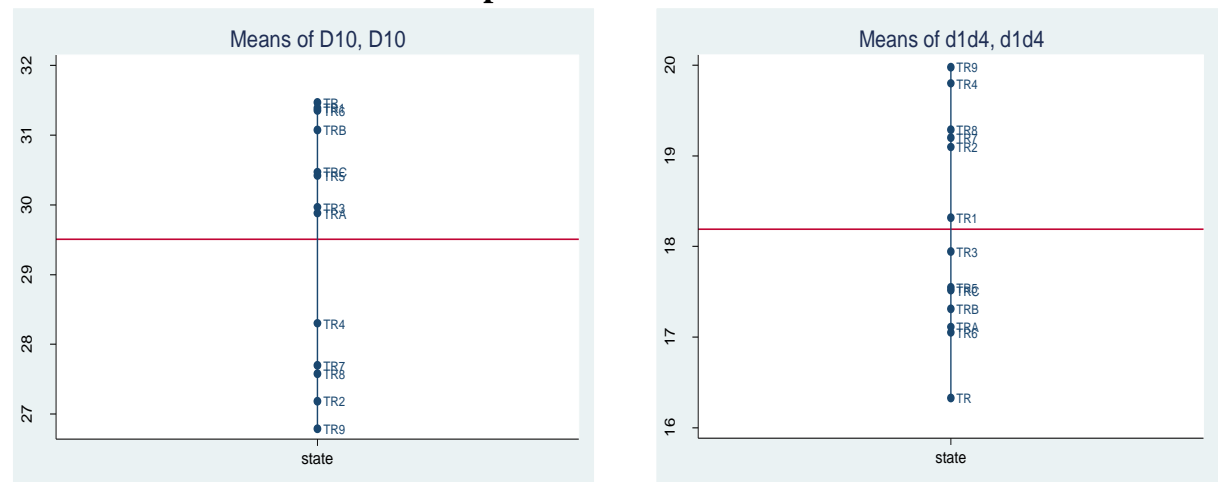

(TurkStat, 2016-2017)

In addition, considering the regional mean values of the Gini coefficient, the regions with the highest D10 are also found to be the regions with the highest Gini coefficient and Palma ratio. For regions other than (TR1), it is possible to generalize that the Palma ratio is lower for the regions with the highest D1-D4 mean. In this context, the (TR1) region stands at a more distinct point than other regions.

On the other hand, both on an interregional level, the correlation between the Palma ratio and D10 is higher (positive) than the correlation between the Palma ratio and D1-D4 (negative) for all regions (except (TR3) and (TRC). Similarity between the regional mean levels and the correlation coefficient results indicate a strong relationship between the Palma ratio and the D10 and even between the Gini coefficient and D10 deciles. The difference in the correlation coefficient for (TR6) and (TRC) regions (as stated above) is mainly related to the correlation between the D10 and D1-D4 figures that stay out of the \%95 confidence interval. In addition, the D5-D9 correlation with both metrics is found to be weaker (negative) than others income groups.

High range values for the three income deciles which are also higher than the TR's range values indicate intra-regional inequalities. In particular, the D10 range value (13.72) is noticeable, while the middle deciles range value is (9.2) and the bottom deciles range value is calculated as (6.87). However, the ranking of the standard deviation and the coefficient of variation according to inter-regional income deciles, confirms relative instability of D10. The higher standard deviation and coefficient of variation values of D10 within regions also indicates inter-regional inequalities. 
The mapping of standard deviation for regions it could be suggested that regions with higher and lower standard deviation for the D10 income group also have higher and lower standard deviations for the Palma ratio and the Gini coefficient. Furthermore, considering the standard deviation ranking of regions overlapping with the Palma ratio and the Gini coefficients is apparent. The highest standard deviation of the D10 income deciles belongs to the (TRA) (2.41) and (TR1) (2.40) regions, while the lowest standard deviation is calculated as the (TRC) (0.92) region.

The regions with the highest standard deviation for D1-D4 are (TRA) (1.37), and with the lowest standard deviation is (TR6) (0.71), although lower standard deviation for bottom deciles indicates lower standard deviation values for both metrics, in this case the overlapping trend is as apparent as D10 income groups.

Another fact about dispersion in income groups is related to the standard deviation of middle-income groups, where it is found to be higher than the standard deviation of the bottom deciles. (TR1) has the highest (1.5) value of standard deviation for middle deciles whereas (TR3) has the lowest (0.51). Briefly arranging standard deviation of middle deciles indicates another path different from the bottom and top income deciles.

When change with respect to mean income is investigated, the overall trend is found to be similar with TR's especially with (TR1) and (TR2) as mentioned in the previous section. This is due to the highest proportional change in mean income of the region's D10 deciles and contrary for lower values for D1-D4 and middle deciles. As an overall result, proportional change in the middle-income groups mean with respect to total mean income is almost overlapping. Although, it is observed that proportional change in the bottom deciles has been higher in other regions compared to other income groups. Considering proportional change with GDP per capita and the percentage share of income groups, proportional change in share of D1-D4 is found to be more sensitive to changes in GDP per capita income, whereas a mirror image relation among D10 and D1-D4 has been observed. Another striking result is about proportional change in the middle-income percentage share that is found to be least sensitive to changes, except from (TR1) and (TR2).

Under these given circumstances, regions with a higher Palma ratio and D10 mean income are found to be the regions that have a higher contribution to 'between' regional inequalities, indicating the deterministic process in explaining concentration of income inequality (Eq.2). Especially, the contribution to 'between' group inequality in the case of D10 has been higher for (TR1) and (TRC) regions and also higher in the case of D1-D4 income groups ${ }^{25}$. While regions with the lowest contribution to total inequality also have the lowest contribution to between group inequality by means of D10 [respectively (TR2), 
(TR9), (TR4)]. In this case apart from (TR4), (TR2) and (TR9) regions are found to have less contribution to between group inequalities by means of D1-D4 income groups ${ }^{26}$.

Apart from these, it should be underlined that (as it is seen from figure 11) regional income inequality exists not only of differences in total income but differences in 'within' group inequality. Regarding 'within' group inequality values (Eq.3), once more D10 is found to contribute more to inequality whereas the D1-D4 share has the lowest contribution for each region. Jointly, regions with the lowest total 'within' values ((TR2), (TR9), (TRA)) are found to have relatively lower 'within' values for D10. (TR1), (TR3), (TR5), (TR6) and (TRC) regions could be classified among the regions with the highest 'within' inequality values. Adding to that, these regions have a higher mean of the Gini coefficient and the Palma ratio, with D10 with a lower share of bottom deciles ${ }^{27}$.

Figure: 11

Overall Mean of Within Group

Inequality of Relevant Deciles (2006-2017)

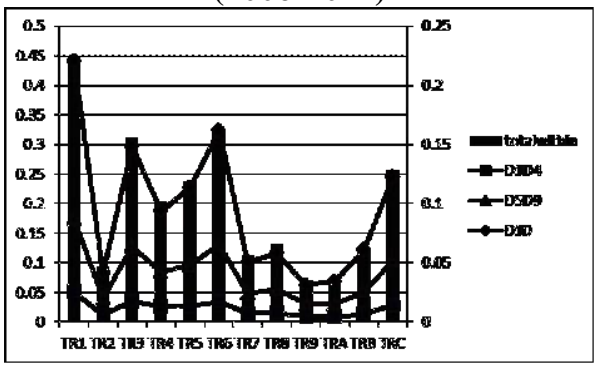

Figure: 12

Overall Mean of Between Group Analysis for Relevant Deciles (2006-2017)

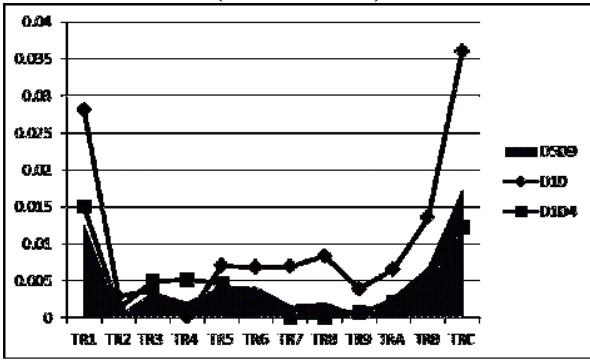

\section{Conclusion}

Within the context of this paper, the primary importance of income deciles rather than the Gini coefficient has been challenged and it aims to contribute to the demonstration of concentration of income inequality in the case of Turkey.

Basic findings of this paper confirm a consistency of axioms of the Palma ratio in the case of Turkey while deeper analysis of income deciles provide important clues on the dimension of asymmetries in income distribution, both at a national and regional level.

${ }^{26}$ For D10 (TR2) (0.002), (TR4) (0.0001), (TR9) (0.003) and for D1-D4; (TR2) (0.0013), (TR4) (0.0051), (TR9) (0.007).

27 For maximum values: (TR1); D10(0.2), D1-D4 (0.05), D5-D9 (0.17), Totalwithin; (0.44), (TR3); D10 (0.148), D1-D4(0.035), D5-D9 (0.128), Totalwithin (0.31), (TR6); D10 (0.16), D1-D4 (0.035), D5-D9 (0.13), Totalwithin (0.33), (TRC); D10 (0.12), D1-D4 (0.028), D5-D9 (0.10), Totalwithin (0.25). For minimum values; (TR9); D10 (0.031), D1-D4 (0.009), D5-D9 (0.03), Totalwithin (0.07), (TR2); D10 (0.04), D1-D4 (0.01), D5-D9 (0.040), Totalwithin (0.09). 
Summing up the robustness of the Palma ratio is evaluated, and it could be underlined that apart from an overlapping trend between the Palma ratio and the Gini coefficient, D10 income deciles and the Gini coefficient has a strong correlation that determines the concentration of income inequality. Even the robustness of the substitution effect of D10 decile against D1-D4 deciles has been outlined. Although the relative stability of middle deciles has been confirmed, for the post 2001 period of Turkey, shifts in middle income deciles and the variation in overall change in middle deciles could not be ignored.

While focusing on regions of Turkey, more diversified results could be realized, however the same trend with the Gini coefficient and the Palma ratio is found to be significant at regional level. The regions with the highest dispersion from the national means values' is found to be more equal by means of the Palma ratio and furthermore for these regions, Mahalanobis distance calculations for D10 and D1-D4 income deciles also diverges from the others. In general, homogenity of middle deciles has been verified fort his case as well. The West Marmara region (TR2), the East Black Sea region (TR9), the East Marmara region (TR4), the Central Anatolia region (TR7) and the West Black Sea region (TR8) belongs to this group. Additionaly by means of the Palma ratio, the West Marmara region, the East Black Sea region (TR9) and the East Marmara region (TR4) could be defined as less unequal regions of Turkey. For these regions, D10 and D1-D4 income decile groups', contribution to total within inequality and between inequalities is found to be lower compared to other regions. It could be noted that D10 decile in the East Marmara region has the lowest contribution to regional inequalities while for the West Marmara and the West Black Sea regions, D1-D4 deciles have the lowest contribution to regional inequalities.

During this period the deterioration of the Palma ratio has been observed for only İstanbul (TR1) and the West Marmara regions, and that is found to be more connected with the decrease in total mean income and the increase in the share of D10 deciles against to D1D4 deciles. Another specific estimation of this paper is about İstanbul that has got outlier characteristics. It could be suggested that richness and poverty dynamics and even the middle-income groups for İstanbul clearly differ from the others. Given the related income decile groups, total within inequality in İstanbul is estimated to have maximum values, in the meantime their contribution to regional inequalities rank among the first in the regions. Besides the Northeast Anatolia region (TRA) and the Aegean region (TR3) has achieved the highest Palma premium for the period of 2006-2017, for these regions, income deciles contribution to within inequality indicate opposite trends because of their different economic structure and distribution dynamics.

Apart from İstanbul; the Meditterrean (TR6), the Aegean, the Southeast Anatolia (TRC) and the Western Anatolia (TR5) are among the regions with the highest within inequality values. For this group of regions, the roots of high within inequality could be estimated by focusing the level of D10. Another characterized result is about the Central East Anatolia (TRB) and the Southeast Anatolia (TRC) regions. Both regions have lower GDP per capita levels and hold high Palma ratio values. Furthermore, apart from İstanbul, these regions are among the specific regions that contribute to regional inequalities and mean values of income deciles of these regions are more proximate to national mean values. 
Tahsin, E. (2019), “An Investigation of the Palma Ratio for Turkey Both on National and Regional Level”, Sosyoekonomi, Vol. 27(41), 151-182.

Additionally, when the proportional change in GDP per capita has been included in the analysis, it is seen that regions with a higher proportional increase in GDP per capita are also the regions with a higher income inequality concentration. It could be concluded that while İstanbul and the South East Anatolia regions GDP per capita levels identify opposite tendencies, however their share of D10 contributes to regional inequalities at the highest levels.

Summing up, the regions that contribute more to income inequality have got strong links with dynamics of centrifugal forces. These given results highlight inverse mirror image of inequalities; poorness and richness between and within regions could be evaluated more plainly. So, the possibility of exploring dimensions of hidden inequality could not be asserted by the Gini coefficient, the main task of the paper leads us to outline the income decile groups of Turkey (and regions), hence, by following the path of the Palma ratio's features, dispersion in richness and poorness has been challenged.

Evidently these facts could be analyzed together with the dynamics of growth regime and the determinants of the income distribution structure of Turkey, both on a national and regional level that has not been investigated within the framework of this paper. In the light of the main results of the given income distribution studies for Turkey, to eliminate asymmetries among the income decile groups, the structure of the value-added share of the GDP together with the investment policies, employment conditions, accumulation of wealth, the poverty dynamics and socioeconomic structure could be addressed. Within this context policy target such as reducing the Palma ratio could be revised regarding taxation and transfer income policies, and composition of social policies given the dynamics of the income distribution relations.

\section{References}

Atkinson, A. \& T. Piketty \& E. Saez (2011), "Top Incomes in the Long Run of History", Journal of Economic Literature, 49(1), 3-71.

Atkinson, A.B. (2003), "Income inequality in OECD countries: Data and Explanations", CESifo Economic Studies, 49(4), 479-513.

Atkinson, T. (1970), “On the Measurement of Inequality”, Journal of Economic Theory, 2, 244-63.

Bağımsız Sosyal Bilimciler BSB (2015), AKP'li Yıllarda Emeğin Durumu, Yordam Kitap, İstanbul.

Bahçe, S. \& A.H. Köse (2017), "Social Classes and the Neo-liberal Poverty Regime in Turkey, 2002-2011", Journal of Contemporary Asia, 47(4), 575-595.

Bakış, O. \& S. Polat (2015), "Wage Inequality in Turkey, 2002-10”, Economics of Transition, 23(1), $169-212$.

Baslevent, C. (2014), "Social Transfers and Income Inequality in Turkey: How Informative Is the Survey of Income and Living Conditions", Ekonomi-tek-International Economics Journal, 3(3), 23-42.

Baslevent, C. (2018), "Household Asset Inequality in Turkey: How Informative is the Survey of Income and Living Conditions?", Economic Research Forum Working Papers, No. 1181.

Bayar, A.A. (2016), The Decomposition of Regional Income Inequalities of Turkey, $<$ https://www.aeaweb.org/conference/2016/retrieve.php?pdfid=1382>, 10.02.2018. 
Bellu, G. \& P. Liberati (2006), “Decomposition of Income Inequality by Subgroups”, Policy Impacts on Inequality, <http://www.fao.org/docs/up/easypol/444/dcmpsnginqulty_sbgrp_052en.pdf>, 10.06.2018.

Bourguignon, F. \& C. Morrisson (2002), "The Size Distribution of Income among World Citizens, 1820-1990", American Economic Review, September, 727-744.

Cingano, F. (2014), "Trends in Income Inequality and its Impact on Economic Growth", OECD Social, Employment and Migration Working Papers, No. 163, OECD Publishing.

Cobham, A. \& A. Sumner (2013), Palma vs Gini: Measuring Post-2015 Inequality, $<$ http://www.thebrokeronline.eu/Blogs/Inequality-debate/Palma-vs-Gini-measuring-post2015-inequality>, 04.02.2019.

Cobham, A. \& A. Sumner (2013a), "Putting the Gini back in the Bottle? The Palma as a Policy Relevant Measure of Inequality", Mimeograph, London: King's College.

Cobham, A. \& A. Sumner (2013b), "Is It All About the Tails? The Palma Measure of Income Inequality", Centre for Global Development Working Paper, No: 343, London: Centre for Global Development.

Cobham, A. \& A. Sumner (2015), Inequality and the Tails: The Palma Proposition and Ratio Revisited, UN DESA.

Cowell, F.A. (2000), "Measurement of inequality”, in: A. Atkinson \& F. Bourguignon (eds.), Handbook of Income Distribution, 1, Elseveir, 87-166.

Dayioğlu, M. \& C. Başlevent (2005), “A Household Level Examination of Regional Income Disparity in Turkey”, METU Studies in Development, 32(2), 275-302.

Dayioglu, M. \& C. Başlevent (2006), "Imputed Rents and Regional Income Inequality in Turkey: A Subgroup Decomposition of the Atkinson Index”, Regional Studies, 40(8), 889-905.

Deininger, K. \& L. Squire (1996), “A New Data Set Measuring Income Inequality”, The World Bank Economic Review, 10(3), 565-591.

Doğruel, F. \& S. Doğruel (2003), “Türkiye'de Bölgesel Gelir Farklılıkları ve Büyüme”, in: A. Köse \& F. Şenses \& E. Yeldan (eds.), İktisat Üzerine Yazılar I Küresel Düzen: Birikim, Devlet ve Sinıflar Korkut Boratav'a Armăgan, 163-182.

Doyle, M. \& J. Stiglitz (2014), "Eliminating Extreme Inequality: A Sustainable Development Goal, 2015-2030”, Ethics and International Affairs, 28(10), 1-7.

Eksi, O. \& M.G. Kırdar (2015), "Emek Gelirlerinin ve Eşitsizliğinin Türkiye İçin Bir Analizi: 20022011”, TEA Discussion Paper, No. 2015/2, Turkish Economic Association, Ankara.

Engberg-Pedersen, L. (2013), Development Goals Post 2015: Reduce Inequality, Danish Institute for International Studies Policy Brief: DIIS.

Eurostat (2018), Glossary: Nomenclature of territorial units for statistics (NUTS), $<$ https://ec.europa.eu/eurostat/statisticsexplained/index.php/Glossary:Nomenclature_of_territorial_units_for_statistics_\%28NU TS\%29>, 20.05.2019.

Filiztekin, A. \& M.A. Çelik (2010), "Regional Income Inequality in Turkey”, Megaron, 5(3), 116127.

Filiztekin, A. (2015), "Income Inequality Trends in Turkey”, İktisat Işsletme ve Finans, 30(350), 6392. 
Tahsin, E. (2019), “An Investigation of the Palma Ratio for Turkey Both on National and Regional Level", Sosyoekonomi, Vol. 27(41), 151-182.

Gezici, F. \& G.J. Hewings (2004), "Regional Convergence and the Economic Performance of Peripheral Areas in Turkey", Review of Urban \& Regional Development Studies, 16(2), 113-132.

Giorgi, G.M. (2011), “The Gini Inequality Index Decomposition. An Evolutionary Study”, in: J. Deutsh \& J. Silber (eds.), The measurement of individual well-being and group inequalities: Essays in memory of ZM Berrebi, Routledge, London, 185-218.

Güven, A. \& B. Dalgıç \& A. Tansel (2016), "Gelir Hareketliliği Gelir Eşitsizliğini Azaltabilir mi? Türkiye Örneği”, METU Studies in Development, 43(2), 549-571.

Hazledine, T. (2014), "Does the Centre Hold? Testing Palma's Proposition (A Comment)", Development and Change, 45(6), 1409-15.

Jenkins, S.P. (1995), “Accounting for Inequality Trends: Decomposition Analyses for the UK, 197186”, Economica, 62(1), 29-63.

Karaca, O. (2018), “Türkiye'de Bölgesel Yakınsamanın 50 Yılı: Yeni Veri Seti ve 1960-2010 Dönemi Analizi”, Sosyoekonomi, 26(35), 207-228.

Krozer, A. (2015), The Inequality We Want: How Much is too Much?, World Institute for Development Economic Research (UNU-WIDER), No. 015.

Lenhardt, A. \& A. Shepherd (2013), A New 'Median' Inequality Indicator, Designed to Support Poverty Eradication, <http://www.thebrokeronline.eu/Blogs/Inequality-debate/A-newmedian-inequality-indicator-designed-to-support-poverty-eradication>, 20.09.2017.

Milanovic, B. (2005), Worlds Apart: Global and International Inequality, 1950-2000, Princeton University Press, Princeton, NJ.

Milanovic, B. (2015), Why I am Still Not Excited by the Palma, <http://glineq.blogspot.co.uk/2015/06/why-i-am-still-not-excitedby-palma.html>, 20.09.2017.

Milanovic, B. (2016), Global inequality: A new Approach for the Age of Globalization, Harvard University Press.

Murawski, S. (2013), Gini, Palma and the Median Inequality Indicator, <http://www.thebrokeronline.eu/Articles/Gini-Palma-and-the-median-inequalityindicator>, 20.09.2017.

Oz, S. (2017), "Is There an Income Convergence Across Provinces of Turkey?", Koç UniversityTUSIAD Economic Research Forum Working Papers, (No. 1711), Koc UniversityTUSIAD Economic Research Forum.

Palma, J.G. (2006), 'Globalizing Inequality: 'Centrifugal' and 'Centripetal' Forces at Work”, DESA Working Paper, 35, New York: United Nations.

Palma, J.G. (2011), "Homogeneous Middles vs. Heterogeneous Tails, and the End of the 'InvertedU': The Share of the Rich is what it's all about", Development and Change, 42(1), 87153.

Palma, J.G. (2013), "Has the Income Share of the Middle and Upper-Middle been Stable over Time, or is its Current Homogeneity across the World the Outcome of a Process of Convergence? The 'Palma Ratio' Revisited", Cambridge Working Papers in Economics, 1437, Cambridge: University of Cambridge.

Palma, J.G. (2014), "Has the Income Share of the Middle and Upper-Middle Been Stable Around the '50/50 Rule', or has it Converged towards That Level? The 'Palma Ratio' Revisited", Development and Change, 45(6), 1416-48. 
Palma, J.G. (2018), Does The Broad Spectrum of Inequality across the World in the Current Era of Neo-Liberal Globalization Reflect a Wide Diversity of Fundamentals, or Just A Multiplicity of Political Settlements and Market Failures?, <http://policydialogue.org/files/publications/papers/Palma-Intl-Rules.pdf>, 10.08.2018.

PovcalNet (2018), <http://iresearch.worldbank.org/PovcalNetNet/povOnDemand.aspx>, 20.01.2019.

Saiz, I. \& K. Donald (2017), "Tackling Inequality through the Sustainable Development Goals: Human Rights in Practice", The International Journal of Human Rights, 21(8), 10291049.

Sefil-Tansever, S. \& O. Kent (2018), "Earnings Inequality in Turkey: A Regional Perspective”, Marmara Íktisat Dergisi, 2(1), 117-136.

Selim, R. \& Ö. Günçavdı \& A.A. Bayar (2014), "Household Income Inequality in Turkey: Functional Income Sources and Regional Ineqaulities", TÜSİAD Report, No: TÜSİAD$\mathrm{T} / 2014-6 / 554$

Şenesen, Ü. (1998), Betimleyici, Sorgulayıcı İstatistik, İstanbul Teknik Üniversitesi, İstanbul.

Smeeding, T. \& J.P. Latner (2015), "PovcalNet, WDI and 'All the Ginis': a critical review”, The Journal of Economic Inequality, 13(4), 603-628.

Sutcliffe, B. (2003), "A More or Less Unequal World? World Income Distribution in the $20^{\text {th }}$ Century", Working Paper, 54, Political Economy Research Institute, University of Massachusetts, Amherst.

Tahsin, E. (2013), "The Gini Illusion of Turkey: An Approach to Inequalities on the Basis of the Palma Ratio", Ekonomik Yaklaşım, 24(89), 73-109.

Tamkoç, M.N. \& O. Torul (2018), “Cross Sectional Facts for Macroeconomists: Wage, Income and Consumption Inequality in Turkey", Bogaziçi University Working Papers, <http://www.econ.boun.edu.tr/torul/csfm.pdf>, 19.05.2019.

Tansel, A. \& B. Dalgıç \& A. Güven (2014), "Wage Inequality and Wage Mobility in Turkey”, IZA Discussion Paper Series, No: 8669, <http://ftp.iza.org/dp8669.pdf>, 30.05.2019.

Tekgüç, H. (2018), "Declining Poverty and Inequality in Turkey: The Effect of Social Assistance and Home Ownership", South European Society and Politics, 1-24.

Torul, O. \& O. Öztunalı (2018), “On Income and Wealth Inequality in Turkey”, Central Bank Review, 18(3), 95-106.

TurkStat (2018), Income and Living Conditions Statistics, <www.tuik.gov.tr>, 30.01.2019.

UNDESA (2013), Inequality Matters: Report on the World Social Situation 2013, New York: UNDESA.

UNDESA (2015), Inequality Measurement Development Issues No. 2, $<$ http://www.un.org/en/development/desa/policy/wess/wess_dev_issues/dsp_policy_02.p $\mathrm{df}>$, 20.07.2018.

UNDP (2016), Income and Social Inequalities in Turkey-2016, <http://www.tr.undp.org/content/turkey/en/home/library/human_development/socialineq ualities.html>, 10.02.2018.

Voitchovsky, S. (2005), "Does the Profile of Income Inequality Matter for Economic Growth?", Journal of Economic Growth, 10(3), 273-296.

Voitchovsky, S. (2009), "Inequality and Economic Growth", The Oxford Handbook of Economic Inequality, Oxford University Press, Oxford. 
World Bank (2016), Poverty and Shared Prosperity 2016: Taking on Inequality,

<https://openknowledge.worldbank.org/bitstream/handle/10986/25078/9781464809583.p

df>, World Bank Publications, 20.07.2018.

World Inequality Lab (2018), World Inequality Report, <https://wir2018.wid.world>, 10.01.2019.

XTLAS (2018), Multidimensional Tests, Mahalanobis,

<https://www.xlstat.com/en/solutions/features/multidimensional-tests>, 10.01.2019.

Yakut A.M. \& E. Voyvoda (2017), "Intertemporal CGE Analysis of Income Distribution in Turkey", ERC Working Papers, No: 17/03, Middle East Technical University,

<https://erc.metu.edu.tr/en/system/files/menu/series17/1703.pdf>, 30.05.2019.

Yildırım, J. \& N. Öcal (2006), "Income Inequality and Economic Convergence in Turkey", Transition Studies Review, 13(3), 559-568.

\section{Appendixes}

Table: 1

Descriptive Statistics for Turkey (TurkStat) (2006-2017)

\begin{tabular}{|l|l|l|l|l|l|}
\hline Stats & Gini coefficient & Palma ratio & D10 & D1-D4 \\
\hline mean & .409 & 1.919 & 8.37 & 16.41 & D5-D9 \\
\hline range & .0037 & .3911233 & 2.15 & 52.16 \\
\hline sd & .009291 & .0992913 & .6475506 & .5828275 \\
\hline variance & .000085 & .0098588 & .4193218 & .3396879 \\
\hline cv & .022768 & .0517153 & .0773405 & .03513 & .3117333 \\
\hline skewness & 1.207528 & 1.388127 & .2464941 & -1.387176 \\
\hline p50 & .404 & 1.907146 & 8.26 & 16.45 & -.63387035 \\
\hline kurtosis & 4.618751 & 4.798711 & 2.180542 & 4.485735 & 52.26 \\
\hline
\end{tabular}

Table: 2

Statistics for Turkey (PovcalNet Data) (2002-2016)

\begin{tabular}{|l|l|l|l|l|l|}
\hline Stats & Gini coefficient & Palma ratio & D10 & D1-D4 \\
\hline mean & 0.405 & 1.909 & 30.69 & 16.11 \\
\hline range & 0.0441 & 0.4689207 & 5.23 & 1.5 \\
\hline sd & 0.0144924 & 0.1510676 & 1.505623 & .5344861 \\
\hline variance & 0.00021 & 0.0228214 & 2.266901 & .2856754 \\
\hline cv & 0.03579999131 & 0.0791006 & .0490447 & .0331736 \\
\hline skewness & 0.0704874 & -0.0237769 & .0106476 & 1.084697 \\
\hline p50 & 0.4018 & 1.872627 & 30.58 & .0218584 & 16.17 \\
\hline kurtosis & 1.709245 & 1.745526 & 2.094282 & 1.594897 \\
\hline
\end{tabular}

Table: 3

Descriptive Statistics Intra-Regional (NUTS-1) (TurkStat) (2006-2017)

\begin{tabular}{|l|l|l|l|l|l|}
\hline Stats & Gini coefficient & Palma ratio & D10 & D1-D4 \\
\hline mean & 0.371 & 1.615 & 29.33 & 18.35 \\
\hline range & 0.134 & 1.210501 & 13.73 & 6.32 \\
\hline sd & 0.0287287 & 0.2403577 & 2.370409 & 1.390268 \\
\hline variance & 0.0008253 & 0.0577718 & 5.618838 & 1.932844 & 9.23 \\
\hline cv & 0.0773881 & 0.1487746 & 0.0808071 & 0.0757625 \\
\hline skewness & -0.0317934 & 0.2905623 & 0.1169964 & 0.0652741 \\
\hline p50 & 0.3715 & 1.601059 & 29.54 & 1.583706 & 0.0302969 \\
\hline kurtosis & 2.327701 & 2.700651 & 2.957325 & -0.4574842 & 2.275038 \\
\hline
\end{tabular}


Table: 4

Maximum and Minimum Values for Descriptive Statistics

(NUTS-1) (TurkStat) (2006-2017)

\begin{tabular}{|c|c|c|c|c|c|c|}
\hline Stats & Mean & range & sd & $\mathrm{cV}$ & kurtosis & skewness \\
\hline \multirow{2}{*}{ Gini coefficient } & $(\mathrm{TR} 6)(0.40)$ & $($ TRA $)(0.1)$ & \multirow{2}{*}{$\begin{array}{c}(\text { TRA })(0.028) \\
(\text { TR6 })(0.01)\end{array}$} & \multirow{2}{*}{$\begin{array}{c}\text { TRA)(0.07) } \\
(\text { TR6) }(0.02)\end{array}$} & \multirow{2}{*}{$\begin{array}{l}(\mathrm{TR} 3)(3.9) \\
(\mathrm{TR} 5)(1.5)\end{array}$} & (TR4)(1.08) \\
\hline & (TR9)(0.33) & $($ TR6) $(0.039)$ & & & & $(\mathrm{TR} 2)(-0.51)$ \\
\hline \multirow{2}{*}{ Palma ratio } & (TR6)(1.84) & $($ TRA $)(1.3)$ & \multirow{2}{*}{$\begin{array}{c}(\text { TR2 })(0.11) \\
(\text { TRA })(0.026)\end{array}$} & \multirow{2}{*}{$\begin{array}{c}(\mathrm{TRC})(0.06) \\
(\mathrm{TR} 1)(0.14)\end{array}$} & \multirow{2}{*}{$\begin{array}{l}(T R 1)(4.4) \\
(T R 5)(1.8) \\
\end{array}$} & $(\mathrm{TR} 3)(1.27)$ \\
\hline & (TR9)(1.34) & (TR2)(0.39) & & & & $($ TRA) $(-0.26)$ \\
\hline \multirow[t]{2}{*}{ D10 } & \multirow{2}{*}{$\begin{array}{l}(\mathrm{TR} 1)(31.39) \\
(\mathrm{TR} 9)(26.79)\end{array}$} & $(\mathrm{TR} 1)(8.25)$ & \multirow{2}{*}{$\begin{array}{l}(\text { TRA })(2.41) \\
(\text { TRC })(0.92)\end{array}$} & $\begin{array}{l}\text { (TRA) }(0.08) \\
(\text { TR1 })(0.076)\end{array}$ & \multirow{2}{*}{$\begin{array}{c}(\mathrm{TR} 1)(4.2) \\
(\mathrm{TR} 5)(1.72)\end{array}$} & $(\mathrm{TR} 1)(1.39)$ \\
\hline & & (TRC)(3.1) & & $(\mathrm{TRC})(0.03)$ & & $(\mathrm{TRB})(-0.38)$ \\
\hline \multirow{2}{*}{ D1-D4 } & \multirow{2}{*}{$\begin{array}{l}\text { (TR9)(19.9) } \\
(\text { TR6)(17.04) }\end{array}$} & (TR1)(4.27) & \multirow{2}{*}{$\begin{array}{c}\text { (TRA) }(1.37) \\
(\text { TR6) }(0.71)\end{array}$} & $($ TRA)(0.8) & \multirow{2}{*}{$\begin{array}{l}\text { (TRA)(3.8) } \\
(\text { TRC) }(1.9)\end{array}$} & (TRA)(1) \\
\hline & & $(\mathrm{TR} 2)(2.5)$ & & $(\mathrm{TR} 1)(0.6)$ & & $(\mathrm{TRC})(-0.07)$ \\
\hline D5-D9 & $\begin{array}{l}\text { (TR2)(53.7) } \\
(\text { TR1)(50.2) }\end{array}$ & $\begin{array}{l}\text { (TR1)(5.62) } \\
(\text { TRC)(2.64) }\end{array}$ & $\begin{array}{l}(\mathrm{TR} 1)(1.5) \\
(\mathrm{TR} 3)(0.5)\end{array}$ & $\begin{array}{l}\text { (TR3)(0.01) } \\
(\mathrm{TR} 1)(0.03)\end{array}$ & $\begin{array}{c}(\mathrm{TR} 1)(3.9) \\
(\mathrm{TR} 8)(1.71)\end{array}$ & $\begin{array}{l}\text { (TRA)(0.65) } \\
\text { (TR1)(-1.09) }\end{array}$ \\
\hline
\end{tabular}

Table: 5

Mean of the Palma Ratio and Gini Coefficient (NUTS-1) (2006-2017)

\begin{tabular}{|c|c|c|}
\hline & Gini coefficient & Palma ratio \\
\hline TR & 0.40 & 1.92 \\
\hline TR1 & 0.38 & 1.72 \\
\hline TR2 & 0.35 & 1.42 \\
\hline TR3 & 0.37 & 1.67 \\
\hline TR4 & 0.34 & 1.43 \\
\hline TR5 & 0.38 & 1.73 \\
\hline TR6 & 0.40 & 1.84 \\
\hline TR7 & 0.35 & 1.44 \\
\hline TR8 & 0.34 & 1.43 \\
\hline TR9 & 0.33 & 1.34 \\
\hline TRA & 0.38 & 1.76 \\
\hline TRC & 0.39 & 1.80 \\
\hline
\end{tabular}

Table: 6

The Palma Ratio and the Gini Coefficient Values (TurkStat)

\begin{tabular}{|c|c|c|c|c|}
\hline & 2006 & 2006 & 2017 & 2017 \\
\hline Stats & Gini coefficient & Palma ratio & Gini coefficient & Palma ratio \\
\hline TR & 0.428 & 2.17 & 0.405 & 2.03 \\
\hline TR1 & 0.375 & 1.65 & 0.443 & 2.34 \\
\hline TR2 & 0.35 & 1.41 & 0.371 & 1.60 \\
\hline TR3 & 0.426 & 2.11 & 0.363 & 1.53 \\
\hline TR4 & 0.392 & 1.79 & 0.342 & 1.41 \\
\hline TR5 & 0.413 & 1.98 & 0.372 & 1.59 \\
\hline TR6 & 0.421 & 2.05 & 0.382 & 1.67 \\
\hline TR7 & 0.342 & 1.37 & 0.334 & 1.33 \\
\hline TR8 & 0.372 & 1.59 & 0.335 & 1.34 \\
\hline TR9 & 0.378 & 1.65 & 0.325 & 1.25 \\
\hline TRA & 0.381 & 1.62 & 0.324 & 1.23 \\
\hline TRB & 0.404 & 1.87 & 0.369 & 1.55 \\
\hline TRC & 0.396 & 1.80 & 0.358 & 1.49 \\
\hline
\end{tabular}

